WellBeing International

WBI Studies Repository

$11-2013$

\title{
An Analysis of the Use of Dogs in Predicting Human Toxicology and Drug Safety
}

Jarrod Bailey

British Union for the Abolition of Vivisection

Michelle Thew

British Union for the Abolition of Vivisection

Michael Balls

Fund for the Replacement of Animals in Medical Experiments

Follow this and additional works at: https://www.wellbeingintlstudiesrepository.org/acwp_lab

Part of the Animal Experimentation and Research Commons, Animal Studies Commons, and the Other Business Commons

\section{Recommended Citation}

Bailey, J., Thew, M., \& Balls, M. (2013). An analysis of the use of dogs in predicting human toxicology and drug safety. Altern Lab Anim, 41(5), 335-50.

This material is brought to you for free and open access by WellBeing International. It has been accepted for inclusion by an authorized administrator of the WBI Studies Repository. For more information, please contact wbisr-info@wellbeingintl.org.

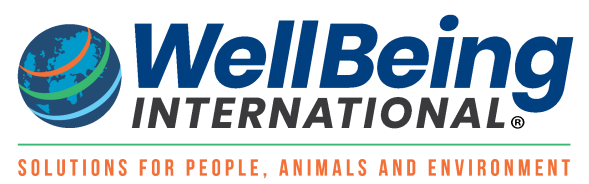




\title{
An Analysis of the Use of Dogs in Predicting Human Toxicology and Drug Safety
}

\author{
Jarrod Bailey, ${ }^{1}$ Michelle Thew ${ }^{1}$ and Michael Balls ${ }^{2}$ \\ ${ }^{1}$ British Union for the Abolition of Vivisection (BUAV), London, UK; ${ }^{2} \mathrm{C} / \mathrm{o}$ Fund for the Replacement of \\ Animals in Medical Experiments (FRAME), Nottingham, UK
}

\begin{abstract}
Summary - Dogs remain the main non-rodent species in preclinical drug development. Despite the current dearth of new drug approvals and meagre pipelines, this continues, with little supportive evidence of its value or necessity. To estimate the evidential weight provided by canine data to the probability that a new drug may be toxic to humans, we have calculated Likelihood Ratios (LRs) for an extensive dataset of 2,366 drugs with both animal and human data, including tissue-level effects and Medical Dictionary for Regulatory Activities (MedDRA) Level 1-4 biomedical observations. The resulting LRs show that the absence of toxicity in dogs provides virtually no evidence that adverse drug reactions (ADRs) will also be absent in humans. While the LRs suggest that the presence of toxic effects in dogs can provide considerable evidential weight for a risk of potential ADRs in humans, this is highly inconsistent, varying by over two orders of magnitude for different classes of compounds and their effects. Our results therefore have important implications for the value of the dog in predicting human toxicity, and suggest that alternative methods are urgently required.
\end{abstract}

Key words: canine, dog, drug development, preclinical testing, toxicology.

Address for correspondence: Jarrod Bailey, British Union for the Abolition of Vivisection (BUAV), 16a Crane Grove, London N7 8NN, UK.

E-mail: jarrod.bailey@mac.com

\section{Introduction}

It is generally assumed that testing new pharmaceuticals on animals helps to ensure human safety and efficacy. Regulatory agencies worldwide require preclinical trials (e.g. 1, 2), which involve at least two species - typically one rodent and one nonrodent species - to determine toxicity and pharmacokinetics. The expectation is that additional data from the non-rodent will detect adverse effects not detected by rodent tests. Despite the current dearth of new drug approvals and meagre pipelines (e.g. 3, 4), this practice continues, with little supportive evidence of its value or necessity (5).

Dogs are used in significant numbers in science - approximately 90,000 are used per annum across the EU and the USA, according to the latest available figures (6-8). About $80 \%$ of this use is as the non-rodent species in the evaluation of pharmaceutical safety and efficacy (6). However, only limited evaluations of the reliability of the canine model for this purpose have been conducted, chiefly due to the difficulty of accessing relevant data, most of which are unpublished and proprietary to pharmaceutical companies. Those evaluations that have been conducted have usually employed 'concordance' metrics (e.g. 9), which various authors have interpreted as the true positive rate ('sensitivity') or the Positive Predictive Value (PPV). While these metrics are appropriate for assessing the reliability of a diagnostic test for a specific disorder (e.g. HIV infection), the insights they provide depend critically on the question being asked of the diagnostic test. However, they are not appropriate for assessing the salient question at issue with animal models, which is whether or not they contribute significant weight to the evidence for or against the toxicity of a given compound in humans. Overcoming this key problem almost entirely overlooked by previous authors requires a precise specification of the various terms used (see Methods). Briefly, the appropriate metrics are Likelihood Ratios (LRs; 10): the Positive Likelihood Ratio (PLR) and the inverse Negative Likelihood Ratio (iNLR). Therefore, there is clearly a need for the kind of statistically-appropriate critical analysis that we provide here. The dataset we have used is unique, in that it is large and allows the conditional probabilities required for the LRs (PLR/iNLR) to be calculated.

\section{Methods}

Animal models are widely used to assess the risk that a given compound will prove toxic in humans. As with any diagnostic test, their reliability can only be assessed by performing tests in which the same compound is given to both animals and humans, and the presence or absence of toxicity recorded. This leads to a $2 \times 2$ matrix of results, as shown in Figure 1 (11). 
Figure 1: A $2 \times 2$ matrix of results

Compound toxic Compound not

in humans toxic in humans

\begin{tabular}{|c|c|}
\hline a: true positives (TPs) & b: false positives (FPs) \\
\hline c: false negatives (FNs) & $\mathrm{d}$ : true negatives (TNs) \\
\hline
\end{tabular}

The basis of this matrix is that the human data are correct, and the dog data are true/false, if they do/do not match them. The various cells in this matrix allow a variety of diagnostic metrics to be deduced, of which the most familiar and widely used are the true positive rate for the test (or 'sensitivity' $=a /[a+c]$ ), and the true negative rate (or 'specificity' $=d /[d+b]$ ). In previous research into the reliability of animal models as predictors of toxicity in humans, some authors (e.g. 9) have focused on the sensitivity, expressed as the 'true positive concordance rate', or the so-called Positive Predictive Value (PPV), given by $a /(a+b)$, which reflects the probability that human toxicity was correctly identified by the animal model, given that toxicity was observed in the animal model (e.g. 12). However, neither of these metrics is suitable for the role of assessing the evidential weight provided by any toxicity test. In the case of animal models, the sensitivity addresses only the ability of such models to detect toxicity that will subsequently manifest itself in humans. This is a necessary, but not sufficient, measure of evidential weight. Suppose, for example, that the animal model always indicates toxicity found in humans; it would then have a sensitivity of $100 \%$. However, if, in addition, the model always indicates toxicity, even in humans, its evidential value is no better than simply dismissing every compound as toxic from the outset. Thus, a useful toxicity test must also be able to give insight into when toxicity seen in the animal model is not observed in humans, which requires knowledge of the specificity of the test.

There is, of course, an obvious reason for the focus on sensitivity in animal model evaluation: if a compound is found to be positive in an animal model, it is unlikely to go into human evaluation. Nevertheless, the fact remains that sensitivity alone cannot be an adequate guide to the value of animal models.

The case of the PPV is more subtle. This metric is a measure of the probability that human toxicity will be correctly identified, given that the animal model detected toxicity. As such, PPVs are conditional probabilities, the condition being the preexistence of a positive animal test result. This makes PPVs dependent on the prevalence of toxicity in compounds, and thus an inappropriate measure of the reliability of the test with any specific compound (e.g. 10, 13).

Thus, any appropriate metric of the evidential value of animal models requires knowledge of both the sensitivity and the specificity of the model. This, in turn, implies that the appropriate metrics for the evidential weight provided by an animal model are LRs (e.g. 13). In general, these are ratios of functions of the sensitivity and specificity, which can be extracted from the $2 \times 2$ matrix given above. In the specific case of animal models in general, two LRs are relevant. The first is the so-called PLR, which is given by:

$$
\begin{aligned}
\mathrm{PLR} & =\text { sensitivity/(1- specificity }) \\
& =(\mathrm{a} / \mathrm{a}+\mathrm{c}) /(\mathrm{b} / \mathrm{b}+\mathrm{d})
\end{aligned}
$$

This LR captures the ability of an animal model to add evidential weight to the belief that a specific compound is toxic. Any animal model that gives a PLR that is statistically significantly higher than 1.0, can be regarded as contributing evidential weight to the probability that the compound under test will be toxic in humans.

The other relevant LR is the so-called iNLR, given by:

$$
\begin{aligned}
\mathrm{iNLR} & =\text { specificity/( } 1-\text { sensitivity }) \\
& =(\mathrm{d} / \mathrm{b}+\mathrm{d}) /(\mathrm{c} / \mathrm{a}+\mathrm{c})
\end{aligned}
$$

This LR captures the ability of an animal model to add evidential weight to the belief that a specific compound is not toxic: any animal model that gives an iNLR that is statistically significantly higher than 1.0, can be regarded as contributing evidential weight to the probability that the compound under test will not be toxic in humans.

It is worth noting at this point that the above definitions imply that a good animal model for detecting human toxicity is not necessarily also good for detecting an absence of toxicity. That is, a high PLR does not guarantee a high iNLR; this will emerge as a key issue in this study.

The above definitions also underscore the need for data on the human toxicity of compounds that 
fail initial animal tests. Again, a key feature of the current study is that this issue has been overcome via data mining methods. Data were obtained from a leading pharmaceutical safety consultancy, Instem Scientific Limited (Harston, Cambridge, UK; http://www.instem-lss.com 'Safety Intelligence Programme'), with funding provided by FRAME. All the information stemmed from publicly accessible sources, including: PubMed (http:// www.ncbi.nlm.nih.gov/pubmed), the FDA Adverse Event Reporting System (FAERS), DrugBank (http://www.drugbank.ca), and the National Toxicology Program (http://ntp.niehs.nih.gov). Data were available for more than 2,300 drug compounds in humans and preclinical species.

Inference of the good quality of the data used in this evaluation is outlined in the Discussion. Compounds were selected that feature in the FAERS, FDA New Drug Applications (FDA NDAs) and DrugBank. Thus, the drugs selected for this analysis are in clinical use, and have undergone preclinical testing: human and animal data are therefore available for them. A non-redundant list of parent moieties was created, for example, by normalising therapeutic products to their generic names (e.g. Lipitor to Atorvastatin). This yielded 2,366 compounds.

A signature of the effects of each compound was created, focusing on tissue-level effects (e.g. bradycardia and arrhythmic disorder would both be considered to be effects on heart tissues), as well as the individual observations, which were mapped to their MedDRA (Medical Dictionary for Regulatory Activities; http://www.meddramsso.com) counterparts. MedDRA observations are classified into four levels, Level 1 being the most specific and Level 4 providing a more generic 'System Organ Class'. These classifications help to eliminate false positives that may arise from species-specific observations, and help the identification of concordant observations that might otherwise have been missed, by their 'rolling up' into more-generic terms.

LRs were derived for broad tissue-level effects ( $n$ $=52$ ), and more-specific biomedical observations (BMOs; $n=384$ ), mapped to MedDRA classifications (Levels 1 [most specific] to Level 4 [more generic 'organ class']). Fourteen BMO classifications not involving dogs were eliminated from the study. A total of 3,275 comparisons were made between the human and the dog, for 2,366 compounds, involving $436(52+384)$ classifications of effects. The Instem Scientific data on which our analysis was based are shown in the Appendix, and the full set of data, including 95\% Confidence Intervals, are available on the FRAME website (www.frame.org.uk).

With regard to potential bias: $\mathrm{FNs}$ are more common than FPs, since there is a bias resulting from a 'precautionary principle' not to progress positives to human administration. This has been mitigated by limiting the dataset to compounds reported in the FAERS database. Therefore, all the compounds are certain to have proceeded to market, and animal preclinical data are available for these compounds. Specific details of how the FPs that were identified arose were not sought, because they were not pertinent to this analysis, and this was not feasible, given the nature of the dataset. It must be assumed that the dog data were correlated with the human data retrospectively, and/or the human data arose from postmarketing studies, and/or clinical trials were applied for and approved, since the adverse effect(s) in dogs were minor and/or mitigated by other data.

\section{Results}

The inappropriate nature of PPVs is demonstrated in Figure 2, which shows a scatter plot of 'ranked' PPVs against equivalent ranked PLRs. Each PPV and PLR was ranked according to its value for each of the 436 classifications of effects, and these ranks were plotted against each other. The disparity is evidenced by the scatter of points, few of which lie close to the $y=x$ line that shows an ideal correlation. The misclassifications and misplaced assumptions of the accuracy of canine data for the prediction of human adverse drug reactions (ADRs) are clear. For example, MedDRA 'Level 4, Vascular Disorder' was ranked 20/436 with regard to the most favourable classifications for human predictivity based on PPV, but its cognate PLR ranked 404/436 - one of the least predictive. Conversely, MedDRA classification 'Level 2, Ventricular Conduction' ranked $30 / 436$ by PLR, but $406 / 436$ by PPV.

Dog PLRs were generally high (median $~ 28$ ), implying that compounds that are toxic in dogs are likely also to be toxic in humans. However, because the PLRs vary considerably (range 4.7-548.7), with no obvious pattern regarding the form of toxicity, the reliability of this aspect of canine models cannot be generalised or regarded with confidence.

In contrast, the calculated inverse negative LRs (iNLRs) are substantially more consistent, but their median value of 1.11 (range 1.01-1.92) supports the view that dogs provide essentially no evidential weight to this aspect of toxicity testing. Specifically, the fact that a compound shows no toxic effects in dogs provides essentially no insight into whether the compound will also show no toxic effects in humans.

This lack of evidential weight has important implications for the role of dogs in toxicity testing, especially for the pharmaceutical industry. The critical observation for deciding whether a candidate drug can proceed to testing in humans is the absence of toxicity in tests on animals. However, 
Figure 2: Scatter plot illustrating the lack of correlation of PPVs and PLRs of biomedical observations (BMOs) and tissue effects in humans and dogs

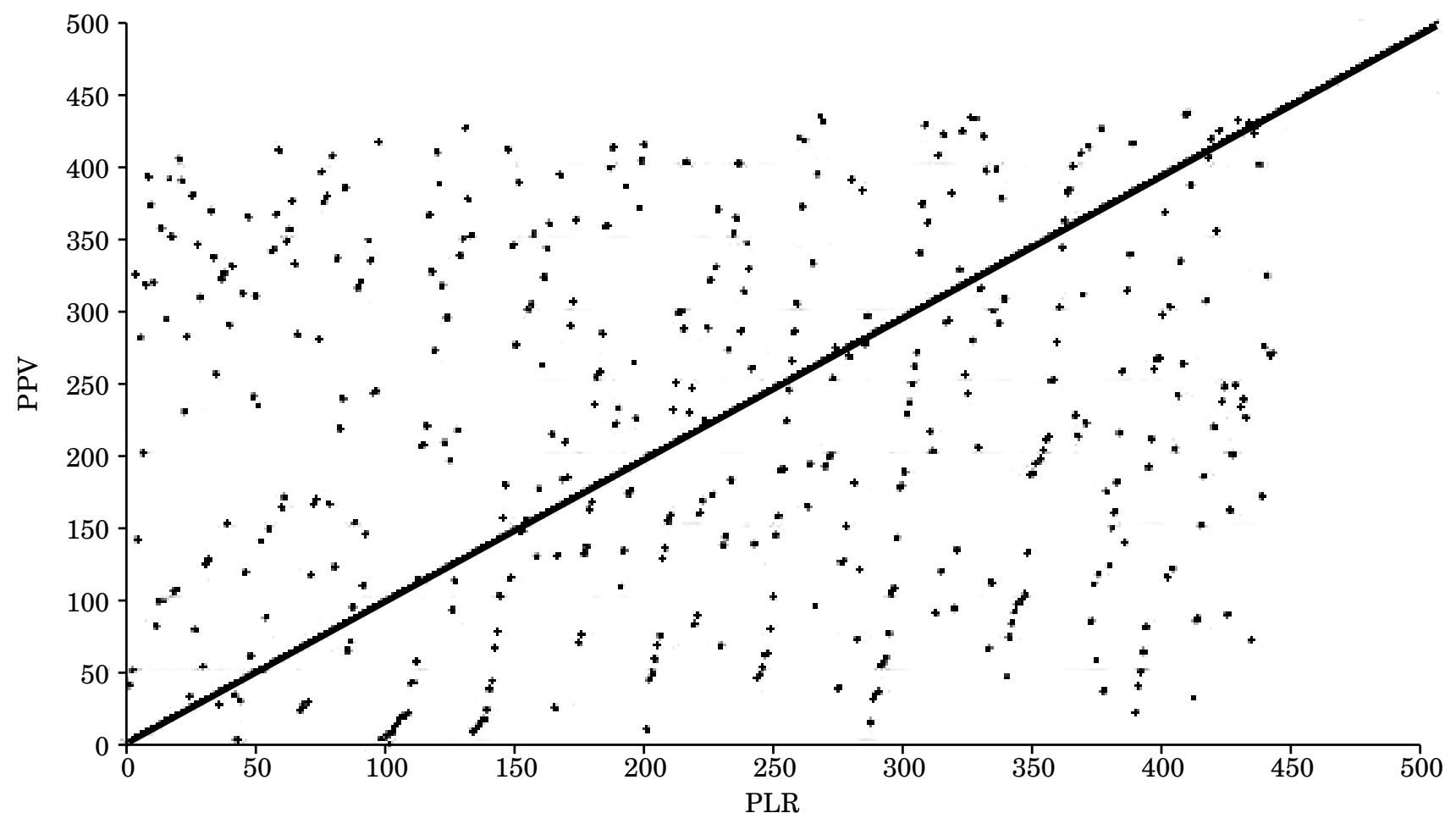

PPVs and PLRs for all 436 results were ordered according to their value, with the highest ranking first and the lowest last. For each BMO and tissue effect, the corresponding PPV and PLR rank were plotted against each other. If a perfect correlation exists, all points should lie on the line, where, for example, the 10th, 50th, and 100th highest PPV value would also be the 10th, 50th, and 100th highest PLR values. However, the significant scatter of the data points demonstrates that little correlation exists between PPV and PLR. For example: the 20th highest PPV ranks only 404/436 for PLR, whereas the 30th highest PLR ranks only 406/436 for PPV.

our findings show that the predictive value of the animal test in this regard is barely greater than that that would be obtained by chance (see below).

\section{Discussion}

The analysis presented here is urgently required, to support informed debate about the worth of animal models in preclinical testing. It is acknowledged among some stakeholders (if not universally among all stakeholders) that assessment of the scientific value of animal data in drug development is necessary, has been scarce, and has been thwarted for decades by the unavailability of relevant data for analysis (e.g. 14). Nevertheless, primarily due to concerns over privacy and commercial interests, data sharing and making data available continue to be resisted, in spite of assurances to the contrary from industry (14).

Those few analyses that have been done, tend to reflect unfavourably on animal models, including the dog. In 2012, a study that expressly set out to minimise bias, showed that $63 \%$ of serious ADRs had no counterparts in animals, and less than $20 \%$ of serious ADRs had a true positive corollary in animal studies (15). Other similar examples exist for testing generally (e.g. 16-18) and more-specifically, for example, in teratology (e.g. 19, 20) and drug-induced liver injury (e.g. 5, 21). One notable study claimed a good concordance for dog and human toxicology (10), though neither the predictive nature of the animal data for humans, nor the evidential weight provided by those data, were addressed (22).

We have, for the first time, addressed the salient question of contribution of evidential weight for or against the toxicity of a given compound in humans by data from dog tests, by using the appropriate metrics of LRs. Furthermore, we have applied the apposite LRs to a dataset of unprecedented scale, to critically question the value of the use of the dog as a preclinical species in the testing of new pharmaceuticals. 
Substantiation of data quality is evidenced by: the methods used to source the data and the assured quality of the databases supplying them (listed above); the ways in which the data had been used recently as a basis for scientific publications and presentations (e.g. 23-26); and the international corporate and academic clients that have used the consultancy and its data (e.g. AstraZeneca; see 23-26). In addition, the impact of 'missing data' (i.e. unpublished data held by pharmaceutical companies) was mitigated by strictly limiting the dataset to drugs "with the greatest chance of having been evaluated in all the species included in the study" (here, dogs and humans). In other words, "...lack of evidence for an association between a compound and a specific BMO demonstrates a real absence of effect, and is not due to missing data" (Instem Scientific Ltd. Analysis Report, unpublished).

Naturally, there must be caveats. Our analysis was limited to data that are published and publicly available. It is widely acknowledged that many animal experimental results/preclinical data remain unpublished and/or proprietary, for a variety of reasons (e.g. 15, 27-30). Such publication bias is a major problem (e.g. 31-34), and, compounded by other factors such as size and quality of the animal studies, variability in the requirements for reporting animal studies, 'optimism bias', and lack of randomisation and blinding (28, 35 ), it means that gauging the true contribution of animal data to human toxicology is impossible at least for third parties without access to pharmaceutical company files. All datasets are imperfect to varying degrees. However, it is only possible to use data which are available, and to ensure that, as far as feasible, those data are of good quality and as free from biases as possible, and that their analysis and derived conclusions are as objective as possible.

It must be made abundantly clear that we, the authors of this report, did not make decisions regarding the toxicity/non-toxicity of drugs, or decide upon or apply any criteria to such decisions. The mining of the data, and the decisions on toxicity of the drugs, were independent of the authors of this paper, and were made by one or both of the authors of the drug/toxicity papers and/or database submissions used, and the data-mining consultancy/curators of the Safety Intelligence Programme, Instem Scientific Limited. Therefore, if any pharmaceutical industry stakeholders have issues or concerns with our conclusions, we would encourage them to conduct further analyses by using their own proprietary data, and/or to facilitate such investigations by making available anonymised data, in accordance with the promotion of transparency encouraged by EU Directive 2010/63/EU (36), as well as to engage fully in constructive discussion and debate with us and our colleagues in animal protection organisations.
Our findings have practical implications for the use of animal models for toxicity testing, especially in the pharmaceutical industry. Reliance on flawed models of toxicity testing leads to two types of failure. If the models have poor PLRs, then there is a risk that many potentially useful compounds will be wrongly discarded, because of 'false positives' produced by the toxicity model. On the other hand, if the models have poor iNLRs, then many toxic compounds will wrongly find their way into human tests, and will fail in clinical trials. The relatively high PLRs found in this study show that animal models may not be leading to the loss of many potentially valuable candidate drugs through false positives. However, our results do imply that many toxic drugs are not being detected by animal models, leading to the risk of unnecessary harm to humans.

In this regard, our findings are entirely consistent with the acknowledged failure of animal models in general to provide guidance on likely toxicity ahead of the entry of compounds into human trials. Drug attrition has increased significantly over the past two decades (e.g. 3, 4, 37-42): 92-94\% of all drugs that pass preclinical tests fail in clinical trials, mostly due to unforeseen toxicities (43-45), and half of those that succeed may be subsequently withdrawn or re-labelled due to ADRs not detected in animal tests (46). ADRs are a major cause of premature death in developed countries (47). A major contributing factor is the inadequacy of preclinical animal tests: one recent study showed that $63 \%$ of ADRs had no counterpart in animals, and less than $20 \%$ had a positive corollary in animal studies (15).

With specific regard to the dog, the most extensive study prior to the report we present here, concluded that $92 \%$ of dog toxicity studies did not provide relevant information in addition to that provided by the rat, and that the other $8 \%$ did not result in the immediate withdrawal of drugs from development, indicating that dog studies are not required for the prediction of safe doses for humans (17). There is a scientific basis for this: among several notable species differences which confound the extrapolation of data from dogs to humans, significant differences between humans and dogs in their cytochrome P450 enzymes (CYPs) - the major enzymes involved in drug metabolism - have been acknowledged for some time, compelling the conclusion that, "...it is readily seen that the dog is frequently not a good metabolic model for man and is poorly comparable to the rat and mouse" (for references, see 46). The lack of knowledge of canine CYPs has been highlighted, which is surprising, considering the extent of the use of dogs in preclinical testing. This problem is likely to be amplified by intra-species differences, as well as by inter-species differences (49). It may therefore be argued that, if many differ- 
ences exist between different breeds or strains of the same species, then extrapolating pharmacokinetic data from that highly variable species to humans must not only be difficult, but must also be patently unreliable.

\section{Conclusions}

This analysis of the most comprehensive quantitative database of publicly-available animal toxicity studies yet compiled, suggests that dogs are highly inconsistent predictors of toxic responses in humans, and that the predictions they can provide are little better than those that could be obtained by chance or tossing a coin - when considering whether or not a compound should proceed to testing in humans. In other words: “...for any putative source of evidential weight to be deemed useful, its specificity and sensitivity must be such that $\mathrm{LR}+[\mathrm{PLR}]>1$. Tossing a coin contributes no evidential weight to a given hypothesis, as the sensitivity and specificity are the same $-50 \%-$ and thus the $\mathrm{LR}+[\mathrm{PLR}]$ is equal to 1 " (22).

Dog PLRs were generally high, showing that a drug which is toxic in the dog is likely to be toxic in humans. However, they were extremely variable and with no obvious pattern, suggesting this aspect of dog tests cannot be considered particularly reliable or helpful. Further, though not within the scope of this analysis, it is of great interest whether the dog revealed any significant toxicities, that were also present in humans, that other species such as the rat did not. In other words, did the dog 'catch' any true human toxicities not caught by the rat? It has been previously argued that such toxicities are relatively low in number (e.g. the development of just $11 \%$ of new compounds was terminated due to effects uniquely seen in dogs, though the human significance of these could not be determined), which would further diminish any value the canine model may have in this respect (50).

More importantly, while iNLRs were much more consistent, they revealed that dogs provide essentially no evidential weight to this aspect of toxicity testing. Specifically, if a compound shows no toxic effects in dogs, this provides essentially no insight into whether the compound will also show no toxic effects in humans. This is crucial: the critical observation for deciding whether a candidate drug can proceed to testing in humans is the absence of toxicity in tests on animals, and our findings show that the predictive value of the dog test in this regard is barely greater than by chance.

A quantitative example illustrates this. Suppose researchers wish to investigate a candidate compound belonging to a family which prior experience indicates has a 70\% probability of freedom from ADRs in humans. Before conducting tests in humans, the drug is tested in dogs. By using the median iNLR figure found by our study, if the compound shows no sign of toxicity in the dog, the probability that the compound will also show no toxic effects in humans will have been increased by the animal testing from $70 \%$ to $72 \%$. The testing thus contributes essentially no additional confidence in the outcome, but at considerable extra cost, both in monetary terms and in terms of animal welfare. This also has obvious practical relevance to the issue of high attrition rates in clinical trials on new drug candidates.

It is argued that a comprehensive suite of more reliable alternative methods is now available (14, 51, 52). Combined with considerable public concern over the use of dogs in science (53), the high ethical costs of doing so, given the sensitive nature of dogs (e.g. 15, 54), and the expressed desire for the use of dogs as a second species in drug testing to have a scientific, rather than a habitual, basis (14), we conclude that the preclinical testing of pharmaceuticals in dogs cannot currently be justified on scientific or ethical grounds.

\section{Acknowledgements}

The authors are grateful to the British Union for the Abolition of Vivisection (BUAV), the Fund for the Replacement of Animals in Medical Experiments (FRAME), and The Kennel Club (via FRAME), for funding. They thank Robert Matthews for advice on inferential issues, Bob Coleman for his help and encouragement during the inception of this undertaking, and Instem Scientific (previously BioWisdom; Harston, Cambridge, UK) for scientific consultancy and for data analysis on integrated data relating to adverse events in model animal species. The research described in this article is based on the analysis and conclusions of the authors: it has not been subjected to each agency's peer review and policy review; therefore, it does not necessarily reflect the views of the organisations, and no official endorsement should be inferred.

Received 23.05.13; received in final form 11.09.13; accepted for publication 19.09.13.

\section{References}

1. Anon. (2004). Directive 2004/27/EEC of the European Parliament and the Council of 31 March 2004, amending Directive 2001/83/EC on the Community code relating to medicinal products for human use. Official Journal of the European Union L136, 30.04.2004, 34-57.

2. Anon. (2010). Federal Food, Drug and Cosmetics Act. Silver Spring, MD, USA: US Food and Drug Administration. Available at: http://www.fda.gov/ RegulatoryInformation/Legislation/FederalFood DrugandCosmeticActFDCAct/default.htm (Acc- 
essed 11.10.13).

3. Duyk, G. (2003). Attrition and translation. Science, New York 302, 603-605.

4. Kola, I. \& Landis, J. (2004). Can the pharmaceutical industry reduce attrition rates? Nature Reviews Drug Discovery 3, 711-715.

5. Aithal, G.P. (2010). Mind the gap. ATLA 38, Suppl. $1,1-4$.

6. UK Home Office (2013). Statistics of Scientific Procedures on Living Animals - Great Britain 2012. HC 549, 60pp. London, UK: The Stationery Office.

7. USDA (2011). Annual Report. Animal Usage by Fiscal Year - Fiscal Year 2010, 2pp. Riverdale, MD, USA: United States Department of Agriculture (USDA), Animal and Plant Health Inspection Service (APHIS). Available at: http://www. aphis. usda.gov/animal_welfare/efoia/downloads/2010_ Animals_Used_In_Research.pdf (Accessed 05.09. 13).

8. Anon. (2010). Sixth Report on the Statistics on the Number of Animals Used for Experimental and Other Scientific Purposes in the Member States of the European Union. SEC(2010) 1107, 14pp. Brussels, Belgium: European Commission. Available at: http://eurlex.europa.eu/LexUriServ/LexUriServ.do? uri=COM:2010:0511:REV1:EN:PDF (Accessed 10. 10.13).

9. Olson, H., Betton, G., Robinson, D., Thomas, K., Monro, A., Kolaja, G., Lilly, P., Sanders, J., Sipes, G., Bracken, W., Dorato, M., Van Deun, K., Smith, P., Berger, B. \& Heller, A. (2000). Concordance of the toxicity of pharmaceuticals in humans and in animals. Regulatory Toxicology \& Pharmacology 32, 56-67.

10. Altman, D.G. \& Bland, J.M. (1994). Diagnostic tests 2: Predictive values. British Medical Journal 309, 102.

11. Anon. (2012). Likelihood Ratios. Oxford, UK: Centre for Evidence Based Medicine (CEBM). Available at: http://www.cebm.net/index.aspx?o= 1043 (Accessed 10.10.13).

12. Greek, R. \& Menache, A. (2013). Systematic reviews of animal models: Methodology versus epistemology. International Journal of Medical Sciences 10, 206-221.

13. Grimes, D.A. \& Schulz, K.F. (2005). Refining clinical diagnosis with likelihood ratios. Lancet $\mathbf{3 6 5}$, 1500-1505.

14. Hasiwa, N., Bailey, J., Clausing, P., Daneshian, M., Eileraas, M., Farkas, S., Gyertyan, I., Hubrecht, R., Kobel, W., Krummenacher, G., Leist, M., Lohi, H., Miklosi, A., Ohl, F., Olejniczak, K., Schmitt, G., Sinnett-Smith, P., Smith, D., Wagner, K., Yager, J.D., Zurlo, J. \& Hartung, T. (2011). Critical evaluation of the use of dogs in biomedical research and testing in Europe. ALTEX 28, 326-340.

15. van Meer, P.J., Kooijman, M., Gispen-de Wied, C.C., Moors, E.H. \& Schellekens, H. (2012). The ability of animal studies to detect serious post marketing adverse events is limited. Regulatory Toxicology \& Pharmacology 64, 345-349.

16. Igarashi, T., Nakane, S. \& Kitagawa, T. (1995). Predictability of clinical adverse reactions of drugs by general pharmacology studies. Journal of Toxicological Sciences 20, 77-92.

17. Broadhead, C.L., Jennings, M. \& Combes, R. (1999). A Critical Evaluation of the Use of Dogs in the Regulatory Toxicity Testing of Pharmaceuticals, 106pp. Nottingham, UK: Fund for the Replacement of Animals in Medical Experiments (FRAME).

18. Litchfield, J.T.J. (1962). Symposium on clinical drug evaluation and human pharmacology. XVI. Evaluation of the safety of new drugs by means of tests in animals. Clinical Pharmacology \& Therapeutics 3, 665-672.

19. Bailey, J. (2008). Developmental toxicity testing: Protecting future generations? ATLA 36, 718-721.

20. Schardein, J. (2000). Chemically Induced Birth Defects, 3rd edn, 1019pp. Boca Raton, FL, USA: CRC Press.

21. Spanhaak, S., Cook, D., Barnes, J. \& Reynolds, J. (2008). Species Concordance for Liver Injury, 6pp. Cambridge, UK: Biowisdom Ltd. Available at: http://www.biowisdom.com/files/SIP_Board_Species _Concordance.pdf (Accessed 10.10.13).

22. Matthews, R.A. (2008). Medical progress depends on animal models - doesn't it? Journal of the Royal Society of Medicine 101, 95-98.

23. Barnes, J.C., Matis, S., Kenna, G., Swinton, J., Bradley, P.M., Day, N.C., Reed, J.Z., Reynolds, J. \& Cook, D. (2008). The Safety Intelligence Program: An Intelligence Network for Drug-induced Liver Injury, 2pp. Cambridge, UK: Biowisdom Ltd. Available at: http://bioblog.instem.com/downloads/ Carboxylic_acids_A4.pdf (Accessed 10.10.13).

24. Sidaway, J.R.M., Roberts, S., Huby, R., Nicholson, A., Pemberton, J., South, M., Noeske, T., Engkvist, O., Bradley, P. \& Reed, J. (2012). Drug Toxicities Associated With Pharmacological Activity: Using Harmonised Data to Make the 'Known'Visible, 2pp. Macclesfield, UK: Safety Assessment, AstraZeneca. Available at: http://bioblog.instem.com/wp-content/ uploads/downloads/2012/03/SOT2012_make-theknown-visible_poster.pdf (Accessed 10.10.13).

25. Fourches, D., Barnes, J.C., Day, N.C., Bradley, P., Reed, J.Z. \& Tropsha, A. (2010). Cheminformatics analysis of assertions mined from literature that describe drug-induced liver injury in different species. Chemical Research in Toxicology 23, 171-183.

26. Greco, I., Day, N., Riddoch-Contreras, J., Reed, J., Soininen, H., Kloszewska, I., Tsolaki, M., Vellas, B., Spenger, C., Mecocci, P., Wahlund, L.O., Simmons, A., Barnes, J. \& Lovestone, S. (2012). Alzheimer's disease biomarker discovery using in silico literature mining and clinical validation. Journal of Translational Medicine 10, 217.

27. Wandall, B., Hansson, S.O. \& Ruden, C. (2007). Bias in toxicology. Archives of Toxicology 81, 605-617.

28. Hackam, D.G. (2007). Translating animal research into clinical benefit. British Medical Journal 334, 163-164.

29. ter Riet, G., Korevaar, D.A., Leenaars, M., Sterk, P.J., Van Noorden, C.J., Bouter, L.M., Lutter, R., Elferink, R.P. \& Hooft, L. (2012). Publication bias in laboratory animal research: A survey on magnitude, drivers, consequences and potential solutions. PLoS One 7, e43404.

30. Briel, M., Muller, K.F., Meerpohl, J.J., von Elm, E., Lang, B., Motschall, E., Gloy, V., Lamontagne, F., Schwarzer, G. \& Bassler, D. (2013). Publication bias in animal research: A systematic review protocol. Systematic Reviews 2, 23.

31. van der Worp, H.B., Howells, D.W., Sena, E.S., Porritt, M.J., Rewell, S., O'Collins, V. \& Macleod, M.R. (2010). Can animal models of disease reliably inform human studies? PLoS Medicine 7, e1000245. 
32. Sena, E.S., van der Worp, H.B., Bath, P.M., Howells, D.W. \& Macleod, M.R. (2010). Publication bias in reports of animal stroke studies leads to major overstatement of efficacy. PLoS Biology 8, e1000344.

33. Perel, P., Roberts, I., Sena, E., Wheble, P., Briscoe, C., Sandercock, P., Macleod, M., Mignini, L.E., Jayaram, P. \& Khan, K.S. (2007). Comparison of treatment effects between animal experiments and clinical trials: Systematic review. British Medical Journal 334, 197.

34. Schott, G., Pachl, H., Limbach, U., Gundert-Remy, U., Ludwig, W.D. \& Lieb, K. (2010). The financing of drug trials by pharmaceutical companies and its consequences. Part 1: A qualitative, systematic review of the literature on possible influences on the findings, protocols, and quality of drug trials. Deutsches Arzteblatt International 107, 279-285.

35. Kilkenny, C., Parsons, N., Kadyszewski, E., Festing, M.F., Cuthill, I.C., Fry, D., Hutton, J. \& Altman, D.G. (2009). Survey of the quality of experimental design, statistical analysis and reporting of research using animals. PLoS One 4, e7824.

36. Anon. (2010). Directive 2010/63/EU of the European Parliament and of the Council of 22 September 2010 on the protection of animals used for scientific purposes. Official Journal of the European Union L276, 20.10.2010, 33-79.

37. US FDA (2004). Innovation or Stagnation: Challenge and Opportunity on the Critical Path to New Medical Products, 12pp. Silver Spring, MD, USA: US Department of Health and Human Services, Food and Drug Administration. Available at: http://www. fda.gov/ScienceResearch/Special Topics/CriticalPath Initiative/CriticalPathOpportunitiesReports/ucm077 262.htm (Accessed 10.10.13)

38. Issa, A.M., Phillips, K.A., Van Bebber, S., Nidamarthy, H.G., Lasser, K.E., Haas, J.S., Alldredge, B.K., Wachter, R.M. \& Bates, D.W. (2007). Drug withdrawals in the United States: A systematic review of the evidence and analysis of trends. Current Drug Safety 2, 177-185.

39. Bennani, Y.L. (2011). Drug discovery in the next decade: Innovation needed ASAP. Drug Discovery Today 16, 779-792.

40. Eichler, H.G., Aronsson, B., Abadie, E. \& Salmonson, T. (2010). New drug approval success rate in Europe in 2009. Nature Reviews Drug Discovery 9, 355-356.

41. Hughes, B. (2008). 2007 FDA drug approvals: A year of flux. Nature Reviews Drug Discovery 7, 107-109.

42. Hartung, T. (2009). Toxicology for the twenty-first century. Nature, London 460, 208-212.

43. Harding, A. (2004). More compounds failing phase I. FDA chief warns that high drug attrition rate is pushing up the cost of drug development. The Scientist, 6 August 2004. Available at: http:// www.the-scientist.com/?articles.view/articleNo/
23003/title/More-compounds-failing-Phase-I/ (Accessed 10.10.13).

44. Okie, S. (2006). Access before approval - a right to take experimental drugs? New England Journal of Medicine 355, 437-440.

45. Aurup, P. (2012). Er Danmark et Attraktivt Land for Klinisk Forskning? (Is Denmark an Attractive Country for Clinical research?), 23pp. Ballerup, Denmark: MSD Laboratories. Available at: http:// di.dk/SiteCollectionDocuments/Opinion/Sundhed/ Høring/Præsentation\%20-\%20Peter\%20Aurup, $\% 20$ Merck.pdf (Accessed 10.10.13).

46. Anon. (1990). FDA Drug Review: Post Approval Risks 1976-1985. GAO/PEMD-90-15, 132pp. Washington, DC, USA: US General Accounting Office. Available at: http://161.203.16.4/d24t8/141456.pdf (Accessed 10.10.13)

47. Lazarou, J., Pomeranz, B.H. \& Corey, P.N. (1998). Incidence of adverse drug reactions in hospitalized patients: A meta-analysis of prospective studies. Journal of the American Medical Association 279, 1200-1205.

48. Gad, S.C. (2006). Animal Models in Toxicology, 952pp. Boca Raton, FL, USA: CRC Press.

49. Martinez, M.N., Antonovic, L., Court, M., Dacasto, M., Fink-Gremmels, J., Kukanich, B., Locuson, C., Mealey, K., Myers, M.J. \& Trepanier, L. (2013). Challenges in exploring the cytochrome P450 system as a source of variation in canine drug pharmacokinetics. Drug Metabolism Reviews 45, 218230.

50. Broadhead, C.L., Betton, G., Combes, R., Damment, S., Everett, D., Garner, C., Godsafe, Z., Healing, G., Heywood, R., Jennings, M., Lumley, C., Oliver, G., Smith, D., Straughan, D., Topham, J., Wallis, R., Wilson, S. \& Buckley, P. (2000). Prospects for reducing and refining the use of dogs in the regulatory toxicity testing of pharmaceuticals. Human \& Experimental Toxicology 19, 440-447.

51. Spielmann, H., Kral, V., Schäfer-Korting, M., Seidle, T., McIvor, E., Rowan, A. \& Schoeters, G. (2011). The AXLR8 Consortium. Alternative Testing Strategies, Progress Report 2011, 364pp. Berlin, Germany: Institute of Pharmacy, Free University of Berlin. Available at: http://scrtox.eu/ scrtox/images/stories/ AXLR8-2011.pdf (Accessed 10.10.13).

52. Anon. (2007). Toxicity Testing for the 21st Century: $A$ Vision and a Strategy, 216pp. Washington, DC, USA: National Academies Press.

53. Anon. (2009). Public Opinion. London, UK: European Coalition to End Animal Experiments. Available at: http://www.eceae.org/en/what-we-do/ campaigns/12-million-reasons/public-opinion (Accessed 10.10.13).

54. Hare, B., Brown, M., Williamson, C. \& Tomasello, M. (2002). The domestication of social cognition in dogs. Science, New York 298, 1634-1636. 


\section{Appendix}

Table A1: Raw data from Instem Scientific's 'Safety Intelligence Programme', showing the number of drugs associated with ADRs in humans and dogs

\begin{tabular}{|c|c|c|c|c|c|c|c|}
\hline & Parameters & & Nur & nber of $\mathrm{c}$ & rugs & & \\
\hline & Adverse effect: tissue-level or BMO (MedDRA Level 1-4) & $\begin{array}{c}\text { Human/Dog } \\
\text { a (TP) }\end{array}$ & $\begin{array}{c}\text { Dog } \\
\text { b (FP) }\end{array}$ & $\begin{array}{l}\text { Human } \\
\text { c (FN) }\end{array}$ & $\begin{array}{l}\text { Neither } \\
\text { d (TN) }\end{array}$ & $\begin{array}{l}\text { Dog } \\
\text { total }\end{array}$ & $\underset{\text { total }}{\text { Human }}$ \\
\hline 1 & Level 1 - qrs prolongation & 10 & 0 & 22 & 2334 & 10 & 32 \\
\hline 2 & Level 2 - glomerulonephritis and nephrotic syndrome & 13 & 0 & 104 & 2249 & 13 & 117 \\
\hline 3 & Level 2 - kidney neoplastic disorder & 8 & 0 & 57 & 2301 & 8 & 65 \\
\hline 4 & Level 1 - ocular hypertension & 6 & 0 & 17 & 2343 & 6 & 23 \\
\hline 5 & Level 3 - glaucoma and ocular hypertension & 6 & 0 & 19 & 2341 & 6 & 25 \\
\hline 6 & Level 2 - glaucomas (excluding congenital) & 6 & 0 & 19 & 2341 & 6 & 25 \\
\hline 7 & Level 1 - nephrotic syndrome & 8 & 0 & 68 & 2290 & 8 & 76 \\
\hline 8 & Level 2 - renal neoplasms (malignant) & 7 & 0 & 49 & 2310 & 7 & 56 \\
\hline 9 & Level 3 - renal and urinary tract neoplasms (malignant and & & & & & & \\
\hline & unspecified) & 7 & 0 & 50 & 2309 & 7 & 57 \\
\hline 10 & $\begin{array}{c}\text { Level } 2 \text { - urinary tract neoplasms (unspecified malignancy not } \\
\text { elsewhere classified; nec) }\end{array}$ & 6 & 0 & 27 & 2333 & 6 & 33 \\
\hline 11 & Level 1 - kidney neoplastic disorder & 6 & 0 & 27 & 2333 & 6 & 33 \\
\hline 12 & Level 1 - orthostatic hypotension & 10 & 0 & 170 & 2186 & 10 & 180 \\
\hline 13 & Level $2-$ hepatic peroxisome proliferation & 5 & 0 & 16 & 2345 & 5 & 21 \\
\hline 14 & Level 1 - cholestatic jaundice & 7 & 0 & 131 & 2228 & 7 & 138 \\
\hline 15 & Brain & 78 & 1 & 854 & 1433 & 79 & 932 \\
\hline 16 & Level 2 - renal failure and impairment & 62 & 2 & 510 & 1792 & 64 & 572 \\
\hline 17 & Bodily fluid & 474 & 18 & 980 & 894 & 492 & 1454 \\
\hline 18 & Skin & 154 & 7 & 1066 & 1139 & 161 & 1220 \\
\hline 19 & Large intestine & 44 & 2 & 810 & 1510 & 46 & 854 \\
\hline 20 & Kidney & 214 & 11 & 696 & 1445 & 225 & 910 \\
\hline 21 & Heart & 509 & 27 & 727 & 1103 & 536 & 1236 \\
\hline 22 & Liver & 515 & 31 & 853 & 967 & 546 & 1368 \\
\hline 23 & Vasculature & 465 & 28 & 842 & 1031 & 493 & 1307 \\
\hline 24 & Nervous tissue & 165 & 10 & 1001 & 1190 & 175 & 1166 \\
\hline 25 & Level $2-$ cholestasis and jaundice & 47 & 3 & 418 & 1898 & 50 & 465 \\
\hline 26 & Nerve & 43 & 3 & 459 & 1861 & 46 & 502 \\
\hline 27 & Level 4 - cardiac disorder & 480 & 34 & 698 & 1154 & 514 & 1178 \\
\hline 28 & Muscle & 168 & 12 & 829 & 1357 & 180 & 997 \\
\hline 29 & Level 4 - blood and lymphatic system disorders & 28 & 2 & 465 & 1871 & 30 & 493 \\
\hline 30 & Level 4 - hepatobiliary disorder & 472 & 34 & 787 & 1073 & 506 & 1259 \\
\hline 31 & Level 3 - hepatic and hepatobiliary disorders & 338 & 26 & 764 & 1238 & 364 & 1102 \\
\hline 32 & Level 3 - renal disorder & 75 & 6 & 394 & 1891 & 81 & 469 \\
\hline 33 & Ear & 12 & 1 & 444 & 1909 & 13 & 456 \\
\hline 34 & Level 4 - vascular disorder & 415 & 35 & 835 & 1081 & 450 & 1250 \\
\hline 35 & Bodily fluid liver & 304 & 26 & 848 & 1188 & 330 & 1152 \\
\hline 36 & Level 3 - renal disorders (excluding nephropathies) & 113 & 10 & 591 & 1652 & 123 & 704 \\
\hline 37 & Level 4 - skin and subcutaneous tissue disease & 195 & 18 & 619 & 1534 & 213 & 814 \\
\hline 38 & Level 2 - hepatic lipid peroxidation & 32 & 3 & 129 & 2202 & 35 & 161 \\
\hline 39 & Level 4 - investigation & 339 & 32 & 723 & 1272 & 371 & 1062 \\
\hline 40 & Level 1 - kidney failure & 21 & 2 & 292 & 2051 & 23 & 313 \\
\hline
\end{tabular}

All entries are numbered for identification only (column 1). The second column (parameters) indicates the specific biomedical observation (BMO) in question (e.g. 'bradycardia' or 'arrhythmic disorder'), or tissue-level effects (e.g. 'heart', which would encompass these two BMOs). The BMOs were mapped to their MedDRA (Medical Dictionary for Regulatory Activities) counterpart, which are classified into four levels, level 1 being the most specific and level 4 providing a more generic 'System Organ Class'. The number of drugs for which ADRs were observed in each species is shown in columns 3-8. Human/Dog represents drugs for which an ADR was reported in both humans and dogs: these are True Positives (TPs), and correspond to cell ' $a$ ' in the $2 \times 2$ matrix (see Methods, Figure 1). Dog represents drugs for which an ADR was reported in dogs, but not in humans: these are False Positives (FPs), and correspond to cell ' $b$ ' in the $2 \times 2$ matrix. Human represents drugs for which an ADR was reported in humans, but not in dogs: these are False Negatives (FNs), and correspond to cell ' $c$ ' in the $2 \times 2$ matrix. Neither represents drugs for which an absence of ADRs was evident in both humans and dogs: these are True Negatives (TNs), and correspond to cell ' $d$ ' in the $2 \times 2$ matrix. Notably, lack of an association between a compound and a specific BMO was assumed (by the data provider) to demonstrate a real absence of effect, and not be due to missing data. To minimise the impact of missing data, the group of compounds in the dataset were chosen with the greatest chance of having been evaluated in all the species included in the study (see Methods). The total number of drugs exhibiting ADRs in each species, regardless of the presence or absence of ADRs in the other species, is given in the final two columns: Dog $=a+b(T P+F P) ;$ Human $=a+c(T P+F N)$.

nec $=$ not elsewhere classified . 
Parameters

\section{Adverse effect: tissue-level or BMO (MedDRA Level 1-4)}

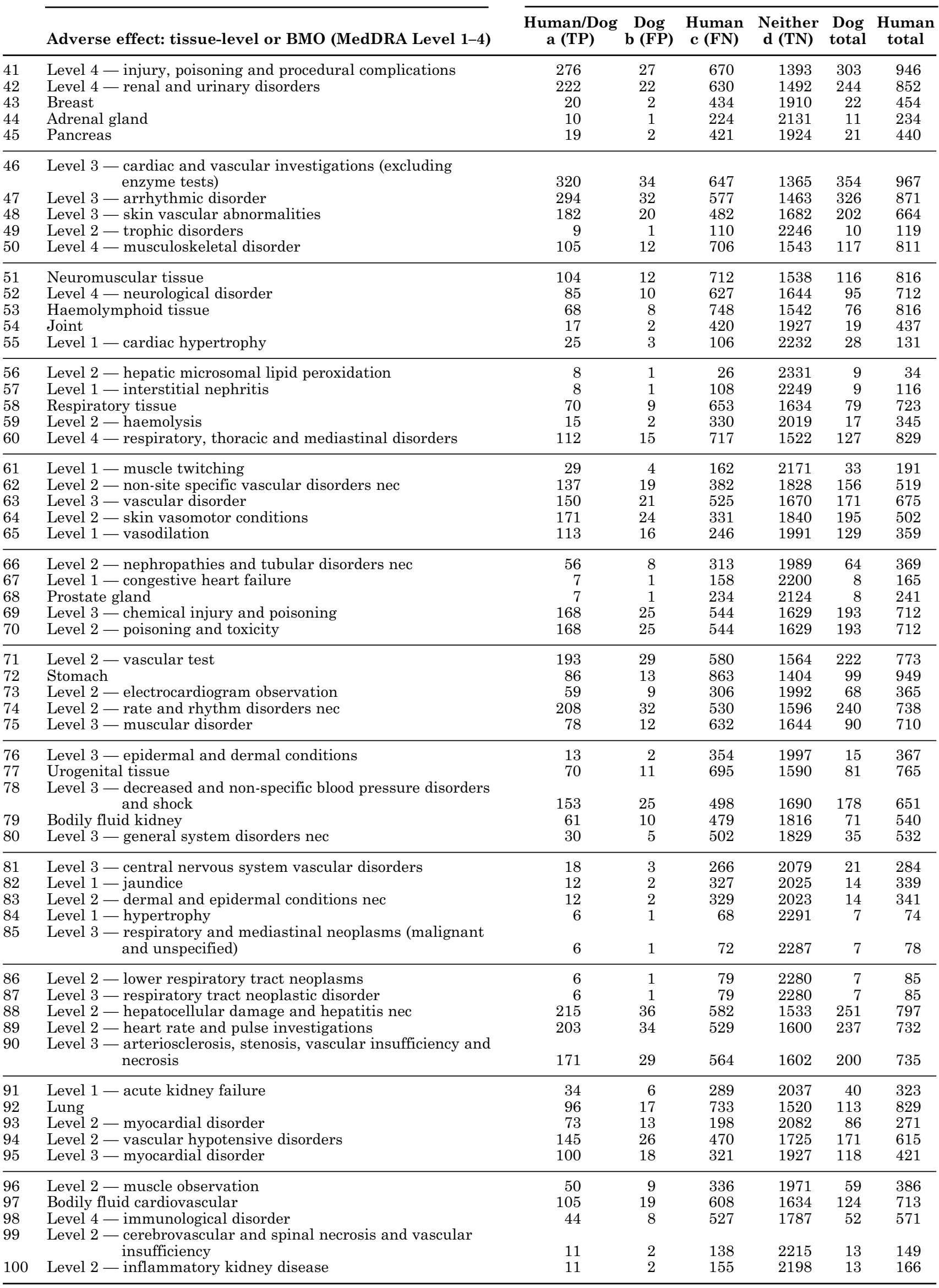

Number of drugs 
Parameters

Number of drugs

Adverse effect: tissue-level or BMO (MedDRA Level 1-4)

Human/Dog Dog Human Neither Dog Human a (TP) b (FP) c (FN) d (TN) total total

\begin{tabular}{|c|c|c|c|c|c|c|}
\hline Uterus & 11 & 2 & 201 & 2152 & 13 & 212 \\
\hline Bladder & 11 & 2 & 293 & 2060 & 13 & 304 \\
\hline Level 3 - cardiac disorder signs and symptoms & 65 & 12 & 509 & 1780 & 77 & 574 \\
\hline Level 3 - hypertension & 96 & 18 & 520 & 1732 & 114 & 616 \\
\hline Pituitary gland & 16 & 3 & 221 & 2126 & 19 & 237 \\
\hline Level 2 - hepatic failure and associated disorders & 16 & 3 & 274 & 2073 & 19 & 290 \\
\hline Level 1 - hypotension & 140 & 27 & 442 & 1757 & 167 & 582 \\
\hline Level 2 - bronchospasm and obstruction & 31 & 6 & 376 & 1953 & 37 & 407 \\
\hline Level 3 - bronchial disorders (excluding neoplasms) & 31 & 6 & 376 & 1953 & 37 & 407 \\
\hline Eye & 77 & 15 & 762 & 1512 & 92 & 839 \\
\hline Level 3 - injury & 120 & 24 & 511 & 1711 & 144 & 631 \\
\hline Level 1 - hepatic apoptosis & 15 & 3 & 111 & 2237 & 18 & 126 \\
\hline Level 2 - central nervous system vascular disorders & 10 & 2 & 90 & 2264 & 12 & 100 \\
\hline Level 3 - haemolyses and related conditions & 15 & 3 & 339 & 2009 & 18 & 354 \\
\hline Level 2 - hepatic collagen synthesis & 5 & 1 & 23 & 2337 & 6 & 28 \\
\hline Level 1 - atrial flutter & 5 & 1 & 26 & 2334 & 6 & 31 \\
\hline Level 1 - glutathione depletion & 5 & 1 & 29 & 2331 & 6 & 34 \\
\hline Level 2 - haematological analyses nec & 5 & 1 & 29 & 2331 & 6 & 34 \\
\hline Level 1 - liver failure & 10 & 2 & 221 & 2133 & 12 & 231 \\
\hline Level 1 - cardiomyocyte apoptosis & 5 & 1 & 32 & 2328 & 6 & 37 \\
\hline Level 2 - cardioprotection & 5 & 1 & 35 & 2325 & 6 & 40 \\
\hline Level 3 - haematology investigations (including blood groups) & 5 & 1 & 40 & 2320 & 6 & 45 \\
\hline Level 1 - lung neoplastic disorder & 5 & 1 & 49 & 2311 & 6 & 54 \\
\hline Level 2 - encephalopathies (toxic and metabolic) & 5 & 1 & 49 & 2311 & 6 & 54 \\
\hline \multirow{2}{*}{$\begin{array}{c}\text { Level } 2 \text { - respiratory tract and pleural neoplasms (malignancy } \\
\text { unspecified nec) }\end{array}$} & 5 & 1 & 50 & 2310 & 6 & 55 \\
\hline & 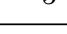 & 1 & 00 & 2010 & & 0 \\
\hline Level 2 - diabetic complications (renal) & 5 & 1 & 52 & 2308 & 6 & 57 \\
\hline Level 1 - abnormal liver function & 10 & 2 & 323 & 2031 & 12 & 333 \\
\hline Level 2 - hepatic enzymes and function abnormalities & 10 & 2 & 323 & 2031 & 12 & 333 \\
\hline Level 1 - toxic hepatitis & 5 & 1 & 94 & 2266 & 6 & 99 \\
\hline Level 3 - cardiac physiological observation & 229 & 46 & 322 & 1769 & 275 & 551 \\
\hline Level 2 - cardiac disorder & 64 & 13 & 378 & 1911 & 77 & 442 \\
\hline Digestive tissue & 49 & 10 & 731 & 1576 & 59 & 780 \\
\hline Level 4 - general disorders and administration site conditions & 58 & 12 & 599 & 1697 & 70 & 657 \\
\hline Level 2 - ventricular arrhythmias and cardiac arrest & 118 & 25 & 390 & 1833 & 143 & 508 \\
\hline $\begin{array}{l}\text { Level } 2 \text { - peripheral vasoconstriction, necrosis and vascular } \\
\text { insufficiency }\end{array}$ & 101 & 22 & 209 & 2034 & 123 & 310 \\
\hline Salivary gland & 9 & 2 & 440 & 1915 & 11 & 449 \\
\hline Level 1 - vasoconstriction & 100 & 23 & 185 & 2058 & 123 & 285 \\
\hline Level 1 - cardiotoxicity & 26 & 6 & 142 & 2192 & 32 & 168 \\
\hline Level 1 - thrombosis & 13 & 3 & 186 & 2164 & 16 & 199 \\
\hline Mouth & 13 & 3 & 297 & 2053 & 16 & 310 \\
\hline Level 2 - ischaemic coronary artery disease & 89 & 21 & 413 & 1843 & 110 & 502 \\
\hline Level 1 - tachycardia & 112 & 27 & 402 & 1825 & 139 & 514 \\
\hline Level 3 - hepatic physiological phenomenon & 267 & 65 & 519 & 1515 & 332 & 786 \\
\hline Level 2 - hypertension & 73 & 18 & 480 & 1795 & 91 & 553 \\
\hline Level 3 - coronary arterial disease & 93 & 23 & 413 & 1837 & 116 & 506 \\
\hline Level 1 - nephrotoxicity & 36 & 9 & 212 & 2109 & 45 & 248 \\
\hline Level 1 - injury & 20 & 5 & 150 & 2191 & 25 & 170 \\
\hline Level 1 - left ventricular hypertrophy & 8 & 2 & 62 & 2294 & 10 & 70 \\
\hline Level 1 - asthma & 12 & 3 & 218 & 2133 & 15 & 230 \\
\hline Level 1 - kidney papillary necrosis & 4 & 1 & 27 & 2334 & 5 & 31 \\
\hline Level 2 - atrial natriuretic factor secretion & 4 & 1 & 28 & 2333 & 5 & 32 \\
\hline Level 2 - renal disorders (congenital) & 4 & 1 & 32 & 2329 & 5 & 36 \\
\hline Level 3 - renal and urinary tract disorders (congenital) & 4 & 1 & 37 & 2324 & 5 & 41 \\
\hline Level 1 - acute lung injury & 4 & 1 & 39 & 2322 & 5 & 43 \\
\hline Level 1 - pulmonary toxicity & 4 & 1 & 46 & 2315 & 5 & 50 \\
\hline Level 2 - herg current & 4 & 1 & 77 & 2284 & 5 & 81 \\
\hline Level 2 - inflammation & 4 & 1 & 109 & 2252 & 5 & 113 \\
\hline Level $2-$ non-site specific gastrointestinal haemorrhages & 4 & 1 & 125 & 2236 & 5 & 129 \\
\hline Level 2 - hepatic and hepatobiliary disorders & 138 & 36 & 524 & 1668 & 174 & 662 \\
\hline Level 1 - torsade de pointes & 19 & 5 & 163 & 2179 & 24 & 182 \\
\hline
\end{tabular}


Number of drugs

Adverse effect: tissue-level or BMO (MedDRA Level 1-4)

\begin{tabular}{|c|c|c|c|c|c|c|c|}
\hline 161 & Level 1 - arrhythmic disorder & 79 & 21 & 383 & 1883 & 100 & 462 \\
\hline 162 & Level 2 - heart failure & 30 & 8 & 326 & 2002 & 38 & 356 \\
\hline 163 & Level 1 - hypertension & 71 & 19 & 477 & 1799 & 90 & 548 \\
\hline 164 & Level 2 - renal and urinary tract injuries nec & 26 & 7 & 185 & 2148 & 33 & 211 \\
\hline 165 & Level 1 - renal injury & 26 & 7 & 185 & 2148 & 33 & 211 \\
\hline 166 & Level 2 - renal structural abnormalities and trauma & 26 & 7 & 189 & 2144 & 33 & 215 \\
\hline 167 & Level 2 - allergic conditions & 26 & 7 & 374 & 1959 & 33 & 400 \\
\hline 168 & Level 3 - allergic conditions & 26 & 7 & 377 & 1956 & 33 & 403 \\
\hline 169 & Level 2 - coronary necrosis and vascular insufficiency & 62 & 17 & 409 & 1878 & 79 & 471 \\
\hline 170 & Level 2 - left ventricular failure & 21 & 6 & 165 & 2174 & 27 & 186 \\
\hline 171 & Level 4 - congenital, familial and genetic disorders & 21 & 6 & 294 & 2045 & 27 & 315 \\
\hline 172 & Level 2 - central nervous system haemorrhages and & & & & & & \\
\hline & cerebrovascular accidents & 7 & 2 & 209 & 2148 & 9 & 216 \\
\hline 173 & Level 3 - lower respiratory tract disorders & & & & & & \\
\hline & (excluding obstruction and infection) & 38 & 11 & 368 & 1949 & 49 & 406 \\
\hline 174 & Bone & 31 & 9 & 398 & 1928 & 40 & 429 \\
\hline 175 & Level $2-$ signs and symptoms & 24 & 7 & 439 & 1896 & 31 & 463 \\
\hline 176 & Level 2 - non-site specific embolism and thrombosis & 17 & 5 & 230 & 2114 & 22 & 247 \\
\hline 177 & Level 2 - non-site specific injuries nec & 20 & 6 & 158 & 2182 & 26 & 178 \\
\hline 178 & Level 1 - ventricular tachyarrhythmia & 10 & 3 & 32 & 2321 & 13 & 42 \\
\hline 179 & Cardiovascular tissue & 73 & 22 & 445 & 1826 & 95 & 518 \\
\hline 180 & Level 1 - long qt interval & 23 & 7 & 186 & 2150 & 30 & 209 \\
\hline 181 & Level 1 - cardiac arrest & 23 & 7 & 211 & 2125 & 30 & 234 \\
\hline 182 & Level 2 - renal disorder & 19 & 6 & 185 & 2156 & 25 & 204 \\
\hline 183 & Level 2 - cardiac conduction abnormality & 44 & 14 & 278 & 2030 & 58 & 322 \\
\hline 184 & Level 1 - bradycardia & 78 & 25 & 271 & 1992 & 103 & 349 \\
\hline 185 & Level $4-$ metabolism and nutrition disorders & 62 & 20 & 368 & 1916 & 82 & 430 \\
\hline 186 & Level 3 - tissue disease & 24 & 8 & 218 & 2116 & 32 & 242 \\
\hline 187 & Level 1 - pulmonary oedema & 18 & 6 & 145 & 2197 & 24 & 163 \\
\hline 188 & Level 4 - eye disorder & 9 & 3 & 88 & 2266 & 12 & 97 \\
\hline 189 & Level $2-$ muscular disorder & 15 & 5 & 286 & 2060 & 20 & 301 \\
\hline 190 & Level 3 - immunological disorder & 12 & 4 & 258 & 2092 & 16 & 270 \\
\hline 191 & Level 3 - cardiac and vascular disorders congenital & 9 & 3 & 173 & 2181 & 12 & 182 \\
\hline 192 & Level 2 - renal observation & 6 & 2 & 85 & 2273 & 8 & 91 \\
\hline 193 & Oesophagus & 9 & 3 & 258 & 2096 & 12 & 267 \\
\hline 194 & Level 3 - gastrointestinal haemorrhage & 6 & 2 & 159 & 2199 & 8 & 165 \\
\hline 195 & Level 2 - gastrointestinal haemorrhage & 6 & 2 & 177 & 2181 & 8 & 183 \\
\hline 196 & Level 1 - hepatic injury & 61 & 21 & 341 & 1943 & 82 & 402 \\
\hline 197 & Level 2 - abdominal injury & 61 & 21 & 343 & 1941 & 82 & 404 \\
\hline 198 & Level 1 - hepatotoxicity & 92 & 32 & 386 & 1856 & 124 & 478 \\
\hline 199 & Musculoskeletal tissue & 23 & 8 & 525 & 1810 & 31 & 548 \\
\hline 200 & Level 2 - pulmonary oedema & 20 & 7 & 197 & 2142 & 27 & 217 \\
\hline 201 & Level 1 - liver disorder & 17 & 6 & 211 & 2132 & 23 & 228 \\
\hline 202 & Level 1 - muscular disorder & 8 & 3 & 113 & 2242 & 11 & 121 \\
\hline 203 & Level 1 - liver cirrhosis & 8 & 3 & 139 & 2216 & 11 & 147 \\
\hline 204 & Nose & 8 & 3 & 401 & 1954 & 11 & 409 \\
\hline 205 & Level 1 - hypoxia & 13 & 5 & 150 & 2198 & 18 & 163 \\
\hline 206 & Level 2 - conditions associated with abnormal gas exchange & 13 & 5 & 151 & 2197 & 18 & 164 \\
\hline 207 & Level 2 - muscle tone abnormalities & 13 & 5 & 232 & 2116 & 18 & 245 \\
\hline 208 & Level 1 - ventricular arrhythmia & 41 & 16 & 159 & 2150 & 57 & 200 \\
\hline 209 & Level 3 - neuromuscular disorder & 23 & 9 & 351 & 1983 & 32 & 374 \\
\hline 210 & Level 3 - heart failure & 53 & 21 & 388 & 1904 & 74 & 441 \\
\hline 211 & Bodily fluid cardiac & 53 & 21 & 443 & 1849 & 74 & 496 \\
\hline 212 & Level 4 - endocrine disorder & 10 & 4 & 125 & 2227 & 14 & 135 \\
\hline 213 & Level 2 - hepatic monooxygenase system & 5 & 2 & 15 & 2344 & 7 & 20 \\
\hline 214 & Level 1 - sudden cardiac death & 5 & 2 & 48 & 2311 & 7 & 53 \\
\hline 215 & Level 3 - encephalopathy & 5 & 2 & 52 & 2307 & 7 & 57 \\
\hline 216 & Thyroid gland & 10 & 4 & 266 & 2086 & 14 & 276 \\
\hline 217 & Level 3 - diabetes-related disorder & 5 & 2 & 63 & 2296 & 7 & 68 \\
\hline 218 & Level 2 - vascular smooth muscle cell proliferation & 5 & 2 & 69 & 2290 & 7 & 74 \\
\hline 219 & Level 1 - acute liver failure & 5 & 2 & 76 & 2283 & 7 & 81 \\
\hline 220 & Level $1-$ muscle rigidity & 5 & 2 & 134 & 2225 & 7 & 139 \\
\hline
\end{tabular}


Parameters

Adverse effect: tissue-level or BMO (MedDRA Level 1-4)
Number of drugs

\begin{tabular}{|c|c|c|c|c|c|}
\hline $\begin{array}{l}\text { Human/Dog } \\
\text { a (TP) }\end{array}$ & $\begin{array}{c}\text { Dog } \\
\text { b (FP) }\end{array}$ & $\underset{c(F N)}{\text { Human }}$ & $\begin{array}{l}\text { Neither } \\
\text { d (TN) }\end{array}$ & $\begin{array}{l}\text { Dog } \\
\text { total }\end{array}$ & $\underset{\text { total }}{\text { Human }}$ \\
\hline 5 & 2 & 144 & 2215 & 7 & 149 \\
\hline 5 & 2 & 147 & 2212 & 7 & 152 \\
\hline 5 & 2 & 198 & 2161 & 7 & 203 \\
\hline 5 & 2 & 220 & 2139 & 7 & 225 \\
\hline 5 & 2 & 270 & 2089 & 7 & 275 \\
\hline 32 & 13 & 227 & 2094 & 45 & 259 \\
\hline 66 & 27 & 359 & 1914 & 93 & 425 \\
\hline 12 & 5 & 182 & 2167 & 17 & 194 \\
\hline 81 & 34 & 130 & 2121 & 115 & 211 \\
\hline 28 & 12 & 61 & 2265 & 40 & 89 \\
\hline 28 & 12 & 115 & 2211 & 40 & 143 \\
\hline 28 & 12 & 117 & 2209 & 40 & 145 \\
\hline 7 & 3 & 77 & 2279 & 10 & 84 \\
\hline 7 & 3 & 175 & 2181 & 10 & 182 \\
\hline 7 & 3 & 240 & 2116 & 10 & 247 \\
\hline 7 & 3 & 280 & 2076 & 10 & 287 \\
\hline 16 & 7 & 128 & 2215 & 23 & 144 \\
\hline 91 & 40 & 201 & 2034 & 131 & 292 \\
\hline 52 & 23 & 285 & 2006 & 75 & 337 \\
\hline 9 & 4 & 56 & 2297 & 13 & 65 \\
\hline 9 & 4 & 117 & 2236 & 13 & 126 \\
\hline 9 & 4 & 121 & 2232 & 13 & 130 \\
\hline 9 & 4 & 216 & 2137 & 13 & 225 \\
\hline 22 & 10 & 301 & 2033 & 32 & 323 \\
\hline 22 & 10 & 367 & 1967 & 32 & 389 \\
\hline 11 & 5 & 133 & 2217 & 16 & 144 \\
\hline 11 & 5 & 298 & 2052 & 16 & 309 \\
\hline 24 & 11 & 206 & 2125 & 35 & 230 \\
\hline 13 & 6 & 246 & 2101 & 19 & 259 \\
\hline 15 & 7 & 277 & 2067 & 22 & 292 \\
\hline 34 & 16 & 238 & 2078 & 50 & 272 \\
\hline 19 & 9 & 181 & 2157 & 28 & 200 \\
\hline 27 & 13 & 91 & 2235 & 40 & 118 \\
\hline 8 & 4 & 60 & 2294 & 12 & 68 \\
\hline 8 & 4 & 79 & 2275 & 12 & 87 \\
\hline 6 & 3 & 50 & 2307 & 9 & 56 \\
\hline 6 & 3 & 50 & 2307 & 9 & 56 \\
\hline 10 & 5 & 201 & 2150 & 15 & 211 \\
\hline 8 & 4 & 171 & 2183 & 12 & 179 \\
\hline 4 & 2 & 39 & 2321 & 6 & 43 \\
\hline 4 & 2 & 41 & 2319 & 6 & 45 \\
\hline 4 & 2 & 46 & 2314 & 6 & 50 \\
\hline 6 & 3 & 132 & 2225 & 9 & 138 \\
\hline 6 & 3 & 132 & 2225 & 9 & 138 \\
\hline 8 & 4 & 228 & 2126 & 12 & 236 \\
\hline 6 & 3 & 151 & 2206 & 9 & 157 \\
\hline 6 & 3 & 188 & 2169 & 9 & 194 \\
\hline 4 & 2 & 113 & 2247 & 6 & 117 \\
\hline 4 & 2 & 119 & 2241 & 6 & 123 \\
\hline 6 & 3 & 428 & 1929 & 9 & 434 \\
\hline 72 & 37 & 225 & 2032 & 109 & 297 \\
\hline 23 & 12 & 392 & 1939 & 35 & 415 \\
\hline 9 & 5 & 104 & 2248 & 14 & 113 \\
\hline 9 & 5 & 117 & 2235 & 14 & 126 \\
\hline 48 & 27 & 188 & 2103 & 75 & 236 \\
\hline 28 & 16 & 502 & 1820 & 44 & 530 \\
\hline 7 & 4 & 65 & 2290 & 11 & 72 \\
\hline 7 & 4 & 299 & 2056 & 11 & 306 \\
\hline 40 & 23 & 405 & 1898 & 63 & 445 \\
\hline 24 & 14 & 96 & 2232 & 38 & 120 \\
\hline
\end{tabular}


Number of drugs

Adverse effect: tissue-level or BMO (MedDRA Level 1-4)

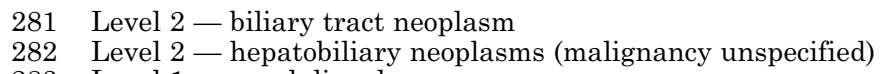

283 Level 1 - renal disorder

284 Level 1 - ventricular tachycardia

285 Level 2 - l-type calcium current

286 Level 1 - haemorrhage

287 Level 1 - cerebral vasospasm

288 Level 3 - ancillary infectious topics

289 Level 2 - inflammatory disorders following infection

290 Level 2 - lower respiratory tract inflammatory and immunologic conditions

291 Level 1 - muscle spasm

292 Level 1 - myocardial disorder

293 Level 2 - cardiac afterload

294 Level 2 - liver cirrhosis

295 Level 1 - ischaemic disease

296 Level 1 - ischaemic cardiomyopathy

297 Level 1 - ventricular fibrillation

298 Level 3 - hepatobiliary neoplasms (malignant and unspecified)

299 Level 1 - st-segment elevation

300 Level 1 - necrosis

301 Level 2 - necrosis

302 Level 2 - hemorrhage

303 Level 1 - apoptosis

304 Level 2 - arterial and aortic injuries

305 Level 1 - neoplastic disorder

8

Number of drugs

Human/Dog Dog Human Neither Dog Human a (TP) b (FP) c (FN) d (TN) total total

$\begin{array}{llllll}24 & 14 & 99 & 2229 & 38 & 123\end{array}$

$\begin{array}{rrrrrr}24 & 14 & 99 & 2229 & 38 & 123 \\ 12 & 14 & 99 & 2229 & 38 & 123\end{array}$

$\begin{array}{lrrrrr}12 & 7 & 148 & 2199 & 19 & 160\end{array}$

$\begin{array}{llllll}12 & 16 & 147 & 2176 & 43 & 174\end{array}$

$\begin{array}{rrrrrr}10 & 6 & 90 & 2260 & 16 & 100\end{array}$

$\begin{array}{llllll}15 & 9 & 269 & 2073 & 24 & 284\end{array}$

$\begin{array}{rrrrrr}5 & 3 & 27 & 2331 & 8 & 32\end{array}$

$\begin{array}{llllll}5 & 3 & 27 & 2331 & 8 & 32 \\ & 3 & 86 & 2272 & 8 & 91\end{array}$

$\begin{array}{llllll}5 & 3 & 86 & 2272 & 8 & 91 \\ & 3 & 86 & 2272 & 8 & 91\end{array}$

$\begin{array}{llllll}5 & 3 & 163 & 2195 & 8 & 168\end{array}$

$\begin{array}{lrllll}8 & 5 & 98 & 2255 & 13 & 106\end{array}$

$\begin{array}{rrrrrr}22 & 14 & 60 & 2270 & 36 & 82 \\ 11 & 7 & 40 & 2308 & 18 & 51\end{array}$

$\begin{array}{rrrrrr}11 & 7 & 40 & 2308 & 18 & 51 \\ 14 & 9 & 239 & 2104 & 23 & 253\end{array}$

$\begin{array}{llllll}14 & 13 & 239 & 2104 & 23 & 253 \\ & 13 & 141 & 2192 & 33 & 161\end{array}$

$\begin{array}{llllll}20 & 13 & 156 & 2177 & 33 & 176\end{array}$

$\begin{array}{llllll}20 & 13 & 156 & 2177 & 33 & 176 \\ 27 & 18 & 127 & 2194 & 45 & 154\end{array}$

$\begin{array}{rrrrrr}24 & 16 & 116 & 2210 & 40 & 140 \\ 9 & 6 & 30 & 2321 & 15 & 39\end{array}$

$\begin{array}{llllll}9 & 6 & 30 & 2321 & 15 & 39 \\ 9 & 6 & 59 & 2292 & 15 & 68\end{array}$

$\begin{array}{rrrrrr}9 & 6 & 60 & 2291 & 15 & 69 \\ 18 & 12 & 372 & 1964 & 30 & 390\end{array}$

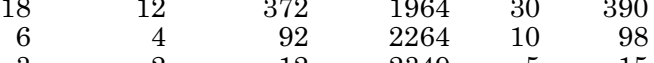

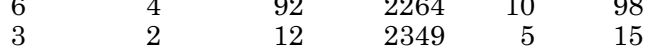

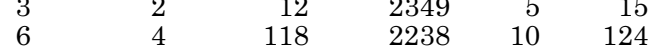
306 Level 2 - neoplasms unspecified (malignancy and site

307 Level 2 - hepatic lipid level

308 Level 1 - renal fibrosis

309 Level 1 - right ventricular hypertrophy

310 Level 1 - hepatic mitochondrial swelling

311 Level 1 - glomerular sclerosis

312 Level 2 - pericardium disorder

313 Small intestine

314 Level 1 - hypersensitive vasculitis

315 Level 1 - inflammation

316 Level 2 - cutaneous vasculitis

317 Level 2 - peripheral vascular disorder

318 Connective tissue

319 Level 2 - muscle tone abnormal

320 Level 1 - pulmonary hypertension

321 Level 2 - systemic vascular resistance

322 Level 2 - hepatic cytochrome p450 level

323 Level 1 - renal impairment

324 Level 2 - hepatic protein biosynthesis

325 Bone-marrow

326 Level 3 - lipid metabolism disorder

327 Level 2 - lipid metabolism and deposit disorders nec

328 Level 1 - hepatic necrosis

329 Level 1 - premature cardiac complex

330 Level 3 - pericardium disorder

331 Level 1 - muscle weakness

332 Level 1 - myocardial infarction

333 Level 2 - pulmonary hypertension

334 Level 3 - electrolyte and fluid balance conditions

335 Level 4 - infections and infestations

336 Level 1 - hepatomegaly

337 Ovary

338 Level 1 - hepatic steatosis

339 Level 1 - cardiogenic shock

340 Testis

\begin{tabular}{|c|c|c|c|c|c|}
\hline 6 & 4 & 122 & 2234 & 10 & 128 \\
\hline 3 & 2 & 20 & 2341 & 5 & 23 \\
\hline 3 & 2 & 22 & 2339 & 5 & 25 \\
\hline 3 & 2 & 22 & 2339 & 5 & 25 \\
\hline 3 & 2 & 36 & 2325 & 5 & 39 \\
\hline 3 & 2 & 39 & 2322 & 5 & 42 \\
\hline 3 & 2 & 47 & 2314 & 5 & 50 \\
\hline 6 & 4 & 233 & 2123 & 10 & 239 \\
\hline 3 & 2 & 85 & 2276 & 5 & 88 \\
\hline 3 & 2 & 96 & 2265 & 5 & 99 \\
\hline 3 & 2 & 102 & 2259 & 5 & 105 \\
\hline 3 & 2 & 143 & 2218 & 5 & 146 \\
\hline 3 & 2 & 204 & 2157 & 5 & 207 \\
\hline 10 & 7 & 208 & 2141 & 17 & 218 \\
\hline 17 & 12 & 94 & 2243 & 29 & 111 \\
\hline 24 & 17 & 79 & 2246 & 41 & 103 \\
\hline 7 & 5 & 50 & 2304 & 12 & 57 \\
\hline 7 & 5 & 276 & 2078 & 12 & 283 \\
\hline 11 & 8 & 61 & 2286 & 19 & 72 \\
\hline 15 & 11 & 302 & 2038 & 26 & 317 \\
\hline 19 & 14 & 137 & 2196 & 33 & 156 \\
\hline 19 & 14 & 137 & 2196 & 33 & 156 \\
\hline 46 & 34 & 177 & 2109 & 80 & 223 \\
\hline 4 & 3 & 51 & 2308 & 7 & 55 \\
\hline 4 & 3 & 72 & 2287 & 7 & 76 \\
\hline 4 & 3 & 174 & 2185 & 7 & 178 \\
\hline 21 & 16 & 296 & 2033 & 37 & 317 \\
\hline 17 & 13 & 108 & 2228 & 30 & 125 \\
\hline 9 & 7 & 107 & 2243 & 16 & 116 \\
\hline 9 & 7 & 381 & 1969 & 16 & 390 \\
\hline 16 & 13 & 116 & 2221 & 29 & 132 \\
\hline 11 & 9 & 327 & 2019 & 20 & 338 \\
\hline 18 & 15 & 135 & 2198 & 33 & 153 \\
\hline 6 & 5 & 83 & 2272 & 11 & 89 \\
\hline 19 & 16 & 260 & 2071 & 35 & 279 \\
\hline
\end{tabular}


Parameters

Number of drugs

Adverse effect: tissue-level or BMO (MedDRA Level 1-4)

\begin{tabular}{|c|c|c|c|c|c|}
\hline$\underset{\text { a (TP) }}{\text { Human/Dog }}$ & $\begin{array}{l}\text { Dog } \\
\text { b (FP) }\end{array}$ & $\underset{\text { c (FN) }}{\text { Human }}$ & $\begin{array}{l}\text { Neither } \\
\text { d (TN) }\end{array}$ & $\begin{array}{l}\text { Dog } \\
\text { total }\end{array}$ & $\underset{\text { total }}{\text { Human }}$ \\
\hline 13 & 11 & 208 & 2134 & 24 & 221 \\
\hline 7 & 6 & 27 & 2326 & 13 & 34 \\
\hline 7 & 6 & 50 & 2303 & 13 & 57 \\
\hline 38 & 35 & 91 & 2202 & 73 & 129 \\
\hline 13 & 12 & 193 & 2148 & 25 & 206 \\
\hline 15 & 14 & 107 & 2230 & 29 & 122 \\
\hline 16 & 15 & 162 & 2173 & 31 & 178 \\
\hline 28 & 27 & 101 & 2210 & 55 & 129 \\
\hline 7 & 7 & 34 & 2318 & 14 & 41 \\
\hline 7 & 7 & 37 & 2315 & 14 & 44 \\
\hline 13 & 13 & 180 & 2160 & 26 & 193 \\
\hline 5 & 5 & 32 & 2324 & 10 & 37 \\
\hline 5 & 5 & 38 & 2318 & 10 & 43 \\
\hline 4 & 4 & 18 & 2340 & 8 & 22 \\
\hline 6 & 6 & 65 & 2289 & 12 & 71 \\
\hline 9 & 9 & 161 & 2187 & 18 & 170 \\
\hline 8 & 8 & 135 & 2215 & 16 & 143 \\
\hline 5 & 5 & 52 & 2304 & 10 & 57 \\
\hline 4 & 4 & 29 & 2329 & 8 & 33 \\
\hline 7 & 7 & 116 & 2236 & 14 & 123 \\
\hline 5 & 5 & 64 & 2292 & 10 & 69 \\
\hline 5 & 5 & 72 & 2284 & 10 & 77 \\
\hline 4 & 4 & 41 & 2317 & 8 & 45 \\
\hline 5 & 5 & 73 & 2283 & 10 & 78 \\
\hline 3 & 3 & 40 & 2320 & 6 & 43 \\
\hline 4 & 4 & 92 & 2266 & 8 & 96 \\
\hline 4 & 4 & 92 & 2266 & 8 & 96 \\
\hline 5 & 5 & 153 & 2203 & 10 & 158 \\
\hline 5 & 5 & 164 & 2192 & 10 & 169 \\
\hline 3 & 3 & 69 & 2291 & 6 & 72 \\
\hline 3 & 3 & 69 & 2291 & 6 & 72 \\
\hline 3 & 3 & 70 & 2290 & 6 & 73 \\
\hline 3 & 3 & 71 & 2289 & 6 & 74 \\
\hline 3 & 3 & 105 & 2255 & 6 & 108 \\
\hline 40 & 41 & 41 & 2244 & 81 & 81 \\
\hline 14 & 15 & 59 & 2278 & 29 & 73 \\
\hline 11 & 12 & 183 & 2160 & 23 & 194 \\
\hline 20 & 22 & 95 & 2229 & 42 & 115 \\
\hline 7 & 8 & 64 & 2287 & 15 & 71 \\
\hline 7 & 8 & 192 & 2159 & 15 & 199 \\
\hline 6 & 7 & 26 & 2327 & 13 & 32 \\
\hline 6 & 7 & 36 & 2317 & 13 & 42 \\
\hline 5 & 6 & 18 & 2337 & 11 & 23 \\
\hline 5 & 6 & 39 & 2316 & 11 & 44 \\
\hline 53 & 66 & 156 & 2091 & 119 & 209 \\
\hline 4 & 5 & 10 & 2347 & 9 & 14 \\
\hline 4 & 5 & 49 & 2308 & 9 & 53 \\
\hline 9 & 12 & 32 & 2313 & 21 & 41 \\
\hline 9 & 12 & 42 & 2303 & 21 & 51 \\
\hline 6 & 8 & 54 & 2298 & 14 & 60 \\
\hline 3 & 4 & 43 & 2316 & 7 & 46 \\
\hline 3 & 4 & 45 & 2314 & 7 & 48 \\
\hline 8 & 11 & 64 & 2283 & 19 & 72 \\
\hline 5 & 7 & 37 & 2317 & 12 & 42 \\
\hline 28 & 40 & 63 & 2235 & 68 & 91 \\
\hline 7 & 10 & 94 & 2255 & 17 & 101 \\
\hline 17 & 25 & 142 & 2182 & 42 & 159 \\
\hline 4 & 6 & 9 & 2347 & 10 & 13 \\
\hline 4 & 6 & 12 & 2344 & 10 & 16 \\
\hline 6 & 9 & 104 & 2247 & 15 & 110 \\
\hline 2 & 3 & 6 & 2355 & 5 & 8 \\
\hline 4 & 6 & 76 & 2280 & 10 & 80 \\
\hline 2 & 3 & 17 & 2344 & 5 & 19 \\
\hline 2 & 3 & 22 & 2339 & 5 & 24 \\
\hline 2 & 3 & 46 & 2315 & 5 & 48 \\
\hline
\end{tabular}

341 Level 1 - heart failure

342 Level 1 - centrilobular hepatic necrosis

343 Level 3 - acid-base disorders

344 Level 2 - action potential duration

345 Level 3 - procedural related injuries and complications nec

346 Level 2 - cardiovascular injuries

347 Level 1 - atrial fibrillation

348 Level 2 - action potential

349 Level 1 - hyperaemia

350 Level 2 - hepatic glutathione level

351 Level 2 - cardiac function diagnostic procedures

352 Level 2 - liver respiration

353 Level 1 - coronary artery vasospasm

354 Level 2 - hepatic RNA synthesis

355 Level 2 - renal vascular and ischaemic conditions

356 Level 1 - ECG abnormality

357 Level 2 - circulatory collapse and shock

358 Level 1 - complete atrioventricular block

359 Level 2 - effective renal plasma flow

360 Level 1 - hepatic fibrosis

361 Level 1 - oedema

362 Level 2 - total fluid volume increased

363 Level 2 - metabolic acidoses (excluding diabetic acidoses)

364 Level 2 - oedema

365 Level 2 - bile acid biosynthesis

366 Level 3 - increased intracranial pressure and hydrocephalus

367 Level 2 - increased intracranial pressure disorders

368 Level 3 - neurological disorder

369 Thymus gland

370 Level 2 - cerebrospinal fluid tests (excluding microbiology)

371 Level 1 - intracranial hypertension

372 Level 3 - neurological, special senses and psychiatric investigations

373 Level 2 - vascular tissue neoplasm

374 Level 2 - nervous system haemorrhagic disorders

375 Level 2 - coronary blood flow

376 Level 2 - bile flow

377 Level 2 - cardiac and vascular procedural complications

378 Level 1 - infarct size

379 Level 2 - coronary arterial disease

380 Level 3 - bile duct disorder

381 Level 2 - hepatic portal blood flow

382 Level 2 - heart weight

383 Level 2 - hepatic glycogen level

384 Level 2 - hepatocyte proliferation

385 Level 2 - liver weight

386 Level 2 - hepatic glucose release

387 Level 1 - left ventricular dysfunction

388 Level 2 - atrioventricular conduction

389 Level 1 - myocardial infarct size

390 Level 2 - hepatic drug metabolism

391 Level 1 - muscle hypotonia

392 Level 2 - left ventricular mass

393 Level 2 - hepatic blood flow

394 Level 1 - myocardial fibrosis

395 Level 2 - renal blood flow

396 Level 1 - atrioventricular block

397 Level 2 - hepatobiliary signs and symptoms

398 Level 1 - coronary artery thrombosis

399 Level 2 - site specific embolism and thrombosis nec

400 Level 2 - renal function

401 Level 2 - ventricular refractory period

402 Level 2 - hepatic cytochrome p450 function

403 Level 1 - high cardiac output

404 Level 1 - chronic hepatitis

405 Level 1 - myocarditis

\begin{tabular}{|c|c|c|}
\hline & $\begin{array}{r}20 \\
7 \\
7\end{array}$ & $\begin{array}{r}22 \\
8 \\
8\end{array}$ \\
\hline & $\begin{array}{r}6 \\
6 \\
5 \\
5 \\
53\end{array}$ & $\begin{array}{r}7 \\
7 \\
6 \\
6 \\
66\end{array}$ \\
\hline & $\begin{array}{l}4 \\
4 \\
9 \\
9 \\
6\end{array}$ & $\begin{array}{r}5 \\
5 \\
12 \\
12 \\
8\end{array}$ \\
\hline & $\begin{array}{r}3 \\
3 \\
8 \\
5 \\
28\end{array}$ & $\begin{array}{r}4 \\
4 \\
11 \\
7 \\
40\end{array}$ \\
\hline posis nec & $\begin{array}{r}7 \\
17 \\
4 \\
4 \\
6\end{array}$ & $\begin{array}{r}10 \\
25 \\
6 \\
6 \\
9\end{array}$ \\
\hline & $\begin{array}{l}2 \\
4 \\
2 \\
2 \\
2\end{array}$ & $\begin{array}{l}3 \\
6 \\
3 \\
3 \\
3\end{array}$ \\
\hline
\end{tabular}


Parameters

Adverse effect: tissue-level or BMO (MedDRA Level 1-4)
Number of drugs

\begin{tabular}{|c|c|c|c|c|c|}
\hline $\begin{array}{c}\text { Human/Dog } \\
\text { a (TP) }\end{array}$ & $\begin{array}{c}\text { Dog } \\
\text { b (FP) }\end{array}$ & $\underset{c(F N)}{\text { Human }}$ & $\begin{array}{c}\text { Neither } \\
\text { d (TN) }\end{array}$ & $\begin{array}{c}\text { Dog } \\
\text { total }\end{array}$ & $\underset{\text { total }}{\text { Human }}$ \\
\hline 2 & 3 & 50 & 2311 & 5 & 52 \\
\hline 2 & 3 & 65 & 2296 & 5 & 67 \\
\hline 2 & 3 & 67 & 2294 & 5 & 69 \\
\hline 2 & 3 & 68 & 2293 & 5 & 70 \\
\hline 5 & 8 & 28 & 2325 & 13 & 33 \\
\hline 5 & 8 & 74 & 2279 & 13 & 79 \\
\hline 15 & 25 & 40 & 2286 & 40 & 55 \\
\hline 3 & 5 & 29 & 2329 & 8 & 32 \\
\hline 3 & 5 & 42 & 2316 & 8 & 45 \\
\hline 4 & 7 & 78 & 2277 & 11 & 82 \\
\hline 9 & 16 & 48 & 2293 & 25 & 57 \\
\hline 6 & 11 & 241 & 2108 & 17 & 247 \\
\hline 6 & 11 & 241 & 2108 & 17 & 247 \\
\hline 8 & 15 & 88 & 2255 & 23 & 96 \\
\hline 9 & 18 & 22 & 2317 & 27 & 31 \\
\hline 8 & 16 & 117 & 2225 & 24 & 125 \\
\hline 5 & 10 & 59 & 2292 & 15 & 64 \\
\hline 2 & 4 & 6 & 2354 & 6 & 8 \\
\hline 2 & 4 & 17 & 2343 & 6 & 19 \\
\hline 2 & 4 & 17 & 2343 & 6 & 19 \\
\hline 2 & 4 & 33 & 2327 & 6 & 35 \\
\hline 3 & 6 & 104 & 2253 & 9 & 107 \\
\hline 13 & 28 & 25 & 2300 & 41 & 38 \\
\hline 15 & 33 & 106 & 2212 & 48 & 121 \\
\hline 5 & 11 & 67 & 2283 & 16 & 72 \\
\hline 4 & 9 & 36 & 2317 & 13 & 40 \\
\hline 7 & 17 & 33 & 2309 & 24 & 40 \\
\hline 2 & 5 & 14 & 2345 & 7 & 16 \\
\hline 2 & 5 & 24 & 2335 & 7 & 26 \\
\hline 2 & 5 & 28 & 2331 & 7 & 30 \\
\hline 2 & 5 & 37 & 2322 & 7 & 39 \\
\hline 13 & 33 & 105 & 2215 & 46 & 118 \\
\hline 3 & 8 & 30 & 2325 & 11 & 33 \\
\hline 3 & 8 & 31 & 2324 & 11 & 34 \\
\hline 7 & 19 & 24 & 2316 & 26 & 31 \\
\hline 12 & 33 & 97 & 2224 & 45 & 109 \\
\hline 2 & 6 & 9 & 2349 & 8 & 11 \\
\hline 5 & 16 & 79 & 2266 & 21 & 84 \\
\hline 5 & 16 & 83 & 2262 & 21 & 88 \\
\hline 7 & 24 & 53 & 2282 & 31 & 60 \\
\hline 2 & 7 & 17 & 2340 & 9 & 19 \\
\hline 5 & 19 & 24 & 2318 & 24 & 29 \\
\hline 5 & 26 & 22 & 2313 & 31 & 27 \\
\hline 2 & 12 & 16 & 2336 & 14 & 18 \\
\hline 2 & 12 & 16 & 2336 & 14 & 18 \\
\hline
\end{tabular}

